\title{
Đánh giá ảnh hưởng của các yếu tố đến hiệu quả xử lý nước thải của việc ứng dụng bùn hạt hiếu khí trên mô hình công nghệ SBR
}

\author{
Phạm Văn Doanh ${ }^{1}$, Trần Thị Việt Nga $^{2}$, Nguyễn Bình Minh ${ }^{2}$ \\ ${ }^{1}$ Trường Đại học Kiến Trúc Hà Nội, Km 10, Đường Nguyễn Trãi, Quận Thanh Xuân , TP Hà Nội, Việt Nam \\ ${ }^{2}$ Trường Đại học Xây Dựng
}

\section{TỪ KHOÁ}

Bể xử lý theo mẻ SBR

Bùn hạt hiếu khí

Xử lý nước thải đô thị

\begin{abstract}
TÓM TẮT
Nuôi cấy và sử dụng bùn hạt hiếu khí trên mô hình công nghệ bể phản ứng theo mẻ SBR trên thế giới bắt đầu từ những năm 1970 và được nghiên cứu sâu trong những năm sau đó với các chất nền dùng để nuôi cấy khác nhau như: glucose, acetate, ethanol, mật mía, đường, tinh bột, phenol, axit phtalic, chloroanilines, rượu tert-butyl, và nước thải tổng hợp khác. Hiệu quả xử lý nước thải (XLNT) của Bùn hạt hiếu khí phụ thuộc vào rất nhiều yếu tố như: Tải trọng chất hữu cơ, thời gian lắng, nhiệt độ, độ pH, lưu lượng sục khí... Trong bài báo này, trình bày sự ảnh hưởng của các yếu tố trên đối với hiệu quả XLNT của ứng dụng Bùn hạt hiếu khí trên mô hình công nghệ SBR quy mô phòng thí nghiệm. Nghiên cứu trên mô hình bể SBR làm bằng nhựa acrylic trong suốt có đường kính ống $0,110(\mathrm{~m})$, chiều cao $1(\mathrm{~m})$, chiều cao chứa nước là $0,8(\mathrm{~m})$, thể tích làm việc của bể là 2,5 (lít). Bể SBR cùng làm việc với 6 chu kỳ trong 1 ngày, thời gian 1 chu kỳ là 4 giờ, trong 1 chu kỳ gồm 4 pha: pha nạp nước 1-2 (phút), pha sục khí 180 (phút), pha nghỉ 20 - 30 (phút), pha xả 10 - 15 (phút). Nước đầu vào cho mô hình là nước thải nhân tạo có tải trọng hữu cơ ở các mức khác nhau. Kết quả thí nghiệm đạt được như sau: loại bỏ trên $92 \% \mathrm{COD}$, $90 \% \mathrm{NH}_{4}{ }^{+}-\mathrm{N}$ đối với nước thải có OLR từ 1,0 - 1,2 kgCOD/m ${ }^{3}$.ngày; trên $90 \% \mathrm{COD}, 89 \% \mathrm{NH}_{4}^{+}-\mathrm{N}_{\text {đối }}$ với nước thải có OLR từ $2,7-3,0 \mathrm{kgCOD} / \mathrm{m}^{3}$.ngày; $\mathrm{COD}$ từ $60-92 \%, \mathrm{NH}_{4}{ }^{+}-\mathrm{N}$ từ $58-90 \%, \mathrm{~T}-\mathrm{N}$ từ 15 - 48 \%, T-P từ 20 - 21 \% nếu lưu lượng sục khí đạt 1,5 - 4,5 (lít/phút); nhiệt độ môi trường từ $25-35^{\circ} \mathrm{C}$ hầu như không ảnh hưởng đến hiệu quả xử lý của bùn hạt hiếu khí; $\mathrm{pH}$ càng thấp thì khả năng xử lý của bùn hạt càng kém và thiếu ổn định. Tổng thời gian thí nghiệm là 55 ngày.
\end{abstract}

\begin{abstract}
Transplanting and application of aerobic granulation in SBR technology has been researched since 1970, this technology has been researched further in recent years with different substances such as: glucose, acetate, ethanol, molasses, sugar, starch, phenol, axit phtalic, chloroanilines, tert-butyl wine, and synthetic wastewater. The efficiency of aerobic granular sludge treatment depends on many factors such as: Organic load, settling time, temperature, $\mathrm{pH}$, aeration flow... This essay describes the the influence of factors on the wastewater treatment efficiency of application of aerobic granulation in SBR technology in the laboratory. Researches on reactors of the same SBR technology with $0,11 \mathrm{~m}$ in diameter and $1 \mathrm{~m}$ in height, water level height $0,8 \mathrm{~m}$, working volume of 2.5 lit. The names of the 2 models are A and $\mathrm{B}$. The reactors were operated sequentially with 6 cycles $/ 1$ day, each cycle is divided into 4 periods, lasting 4 hours: 1 $2 \mathrm{~min}$ of influent filling, $180 \mathrm{~min}$ of aeration, 20 - $30 \mathrm{~min}$ of settling and $10-15 \mathrm{~min}$ of effluent... The results removal over $92 \% \mathrm{COD}, 90 \% \mathrm{NH}_{4}{ }^{+} \mathrm{N}$ with low strength has OLR from $1,0-1,2 \mathrm{kgCOD} / \mathrm{m}^{3}$.day; COD removal over $90 \% \mathrm{COD}, 89 \% \mathrm{NH}_{4}{ }^{+}-\mathrm{N}$ with high strength has OLR from 2,7 - 3,0 kgCOD/ $\mathrm{m}^{3} \cdot \mathrm{ngày}$; removal COD $60-92 \%, \mathrm{NH}_{4}{ }^{+}-\mathrm{N} 58-90 \%$, T-N 15-48 \%, T-P $20-21 \%$ with air supply flow 1,5 4,5(lít/min); the temperature from $25-35^{\circ} \mathrm{C}$ hardly affects the treatment efficiency of aerobic granular sludge; the worse the wastewater treatment capacity and instability of aerobic granules if lower $\mathrm{pH}$. The time for research are 55 days.
\end{abstract}

\section{Mở đầu}

Nuôi cấy và sử dụng bùn hạt hiếu khí trên mô hình công nghệ bể phản ứng theo mẻ(SBR) trên thế giới bắt đầu từ những năm $1970[1,2]$ và đã được nghiên cứu sâu trong những năm sau đó với các chất nền dùng để nuôi cấy khác nhau như: glucose, acetate, ethanol, mật mía, đường, tinh bột, phenol, axit phtalic, chloroanilines, rượu tert-butyl, và nước thải tổng hợp khác $[1,2]$. Ngoài ra các đề tài cũng nghiên cứu đánh giá sự ảnh hường của các yếu tố như: tải trọng chất hữu cơ, thời gian lắng, nhiệt độ, độ $\mathrm{Ph}$, lưu lượng sục khí... đến hiệu quả XLNT của Bùn hạt 
hiếu khí ứng dụng trên mô hình công nghệ SBR. Các nghiên cứu cho thấy hiệu quả XLNT của Bùn hạt hiếu khí có thể bị ảnh hưởng bởi các yếu tố trên ở các mức độ khác nhau và tùy điều kiện môi trường và tùy thuộc vào các loại nước thải khác nhau. So với bùn hoạt tính thông thường bùn hạt hiếu khí có cơ cấu tốt, có khả năng duy trì sinh khối cao, và có thể xử lý các hợp chất độc hại có trong nước thải $[1,2]$. Bùn hạt hiếu khí không chỉ có tác dụng loại bỏ tốt các-bon mà còn có khả năng loại bỏ nitơ và phốt pho, vì vậy mà nó được ứng dụng để xử lý nước thải sinh hoạt, nước thải của các nhà máy chế biến thực phẩm, nước thải chăn nuôi, nước thải công nghiệp. Mỗi cấu trúc bùn hạt hiếu khí là tập hợp các nhóm vi khuẩn khác nhau cần thiết cho quá trình chuyển hóa các hợp chất hữu cơ, thành phần của bùn hạt phụ thuộc vào loại cơ chất. Bùn hạt nó có những ưu điểm sau: mật độ vi sinh vật trong cấu trúc bùn hạt cao, hiệu quả xử lý nước thải cao khi hình thành bùn hạt, chịu được tải trọng hữu cơ cao, kích thước hạt bùn lớn nên có khả năng lắng nhanh, ít bị rửa trôi, chịu được sốc tải, giảm thể tích công trình. Tuy nhiên bùn hạt cũng gặp phải một số nhược điểm như: khó kiểm soát trạng thái và kích thước hạt bùn, các hạt bùn thường không ổn định và rất dễ bị phá vỡ khi có sự thay đổi môi trường.

Tại Việt Nam, có một số đề tài nghiên cứu về sự ảnh hưởng của yếu tố tới hiệu quả XLNT của Bùn hạt hiếu khí còn ít và chưa sâu. Đặc biệt là các nghiên cứu về ảnh hưởng của tải trọng chất hữu cơ, thời gian lắng, nhiệt độ, độ $\mathrm{pH}$, lưu lượng sục khí... đến hiệu quả XLNT của Bùn hạt hiếu khí. Mục đích của nghiên cứu này là: "Đánh giá sự ảnh hưởng của các yếu tố đó đối với hiệu quả XLNT của Bùn hạt hiếu khí trên mô hình công nghệ SBR". Nhóm tác giả đã nghiên cứu trên mô hình công nghệ SBR có nước đầu vào cho mô hình là nước thải nhân tạo có tải trọng hữu cơ ở các mức khác nhau. Giai đoạn thứ nhất sử dụng nước thải có tải trọng hữu cơ thấp OLR từ 1,0 - 1,2 kgCOD/m $\mathrm{m}^{3}$. ngày, giai đoạn thứ 2 sử dụng nước thải có tải trọng hữu cơ cao OLR từ $2,7-3,0 \mathrm{kgCOD} / \mathrm{m}^{3}$. ngày. Thời gian lắng điều chỉnh từ 30 phút xuống 20 phút. Nhiệt độ thí nghiệm là $25-35^{\circ} \mathrm{C}$, lưu lượng sục khí dao động 1,5 - 4,5(lít/phút), độ pH = 6,1 - 8,0.

\section{2. Đối tượng và phương pháp nghiên cứu}

\subsection{Phương pháp xây dựng mô hình thí nghiệm}

Nghiên cứu được thực hiện trên mô hình bể SBR làm bằng nhựa acrylic trong suốt có đường kính ống $0,11 \mathrm{~m}$, cao $1 \mathrm{~m}$, trong đó chiều cao chứa nước là $0,8 \mathrm{~m}$, thể tích làm việc của bể là 2,5 lít. Bể SBR làm việc với 6 chu kỳ/1ngày, thời gian 1 chu kỳ là 4 giờ, trong 1 chu kỳ có 4 pha: pha nạp nước 1 - 2 phút, pha sục khí 180 phút, pha lắng 20 - 30 phút, pha xả 10 - 15 phút. Không khí được đưa vào bể SBR bằng máy sục khí với bộ khuếch tán khí bằng đá bọt được đặt ở đáy bể, lưu lượng sục khí tăng dần từ 1,5 - 4,5 (lít/phút) trong thời gian làm thí nghiệm, trên đường ống dẫn khí lắp đặt bộ van đo lưu lượng sục khí luôn đảm bảo DO từ 2 $4 \mathrm{mg} / \mathrm{l}$. Nhiệt độ thí nghiệm là nhiệt độ phòng dao động trong khoảng 27 - $33^{\circ} \mathrm{C}$. Van xả nước được đặt cách đáy bể $0,4 \mathrm{~m}$ để thể tích xả khoảng 50 \% lượng nước sau một chu kỳ hoạt động. Hệ thống kiểm tra pH, DO đo bằng máy đo cầm tay đo hàng ngày. Toàn bộ các thiết bị như: Bơm cấp nước, máy thổi khí, van xả nước... đều được điều khiển tự động bởi bộ PLC đã được lập trình sẵn theo yêu cầu thí nghiệm.

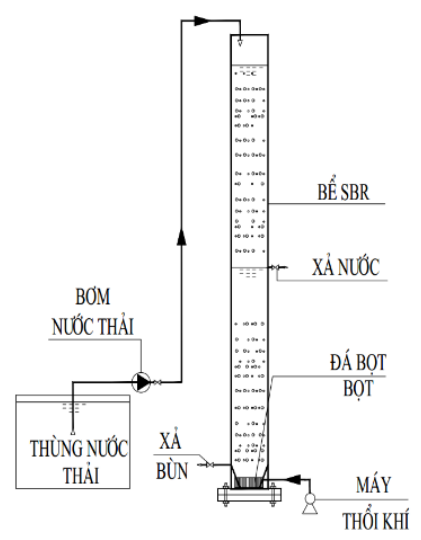

Hình 1. Sơ đồ công nghệ mô hình bể SBR trong phòng thí nghiệm.

\subsection{Bùn hạt thí nghiệm}

Bùn hạt hiếu khí dùng trong thí nghiệm là nguồn bùn được nuôi cấy thành công trong phòng thí nghiệm của nhóm nghiên cứu trong thời gian 4 - 6 tuần với chất nền là Acetate, bùn hạt hiếu khí có kích thước $3-5 \mathrm{~mm}$, màu nâu, cấu trúc tròn đều và đặc, độ bền của hạt cao có thể hoạt động ổn định với lưu lượng sục khí 1,5 - 5 lít/phút và điều kiện nhiệt độ $20-35^{\circ} \mathrm{C}$. Nhóm nghiên cứu đã tách lấy 2,5 lít dung dịch bùn hạt hiếu khí có nồng độ bùn MLSS là 8000 mg/L, MLVSS là 7800 $\mathrm{mg} / \mathrm{L}$.

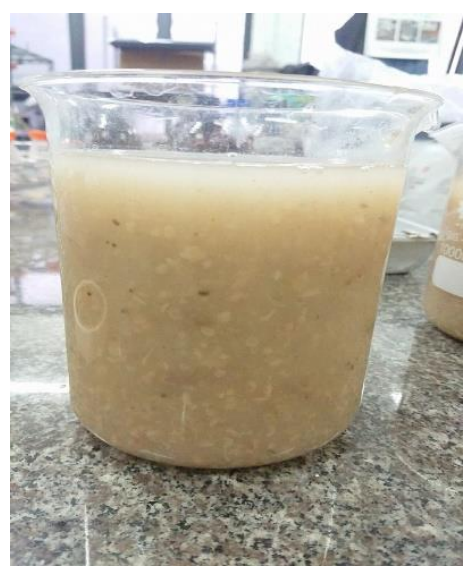

Hình 2. Bùn hạt dùng trong thí nghiệm.

\subsection{Vận hành mô hình thí nghiệm}

Sau quá trình lắp ráp và dựng mô hình, nhóm nghiên cứu thực hiện vận hành thử nghiệm Mô hình bằng nước sạch để kiểm tra các thiết bị như: máy bơm, máy thổi khí, van điện xả nước độ kín, khít của mô hình, đặc biệt là ở các mối nối. Sau quá trình kiểm tra, vận hành thử, tiến hành khởi động mô hình thí nghiệm qua các bước như sau:

Bước 1: Đưa vào 2 bể phản ứng của mô hình 2,5 lít Bùn hạt hiếu khí.

Bước 2: Khởi động mô hình và để mô hình chạy tự động bằng chương trình đã được cài đặt trước trong bộ điều khiển PLC. Duy trì lưu lượng khí cung cấp theo tính toán, sử dụng máy thổi khí lưu lượng cố định, kiểm soát bằng lưu lượng kế. Tiến hành kiểm tra các thiết bị, van khoá hàng ngày, lấy mẫu định kỳ theo kế hoạch. 


\section{Chế độ vận hành mô hình như sau:}

Thời gian làm thí nghiệm: 55 ngày

- Tải trọng hữu cơ đầu vào: OLR từ $1,0-1,2 \mathrm{kgCOD} / \mathrm{m}^{3}$.ngày, và OLR từ $2,7-3,0 \mathrm{kgCOD} / \mathrm{m}^{3}$.ngày.

- Nồng độ ôxy: DO là 2,0 - 4,0 (mg/l).

- Nhiệt độ thí nghiệm: $\mathrm{t}^{0} \mathrm{C}$ là $25-35^{\circ} \mathrm{C}$.

- Độ pH: 6,1 - 8,0.

- Thời gian 1 chu kỳ là 4 giờ , trong 1 chu kỳ có 4 pha: pha nạp nước 1 - 2 phút, pha sục khí 180 phút, pha lắng 20-30 phút, pha xả 10 15 phút.

\subsection{Phân tích kết quả thí nghiệm}

Các thông số sẽ được phân tích trong quá trình nghiên cứu bao gồm: COD, $\mathrm{NH}_{4}^{+}$, pH, DO. Các phương pháp phân tích thông số được thực hiện theo Tiêu chuẩn Việt Nam (TCVN) và được trình bày trong Bảng 1 .

Bảng 1.

Phương pháp phân tích các thông số thí nghiệm

\begin{tabular}{|c|c|l|c|}
\hline $\begin{array}{c}\text { Tên chỉ số } \\
\text { phân tích }\end{array}$ & $\begin{array}{c}\text { Đơn } \\
\text { vị đo }\end{array}$ & Phương pháp phân tích & $\begin{array}{c}\text { Tần suất } \\
\text { phân tích }\end{array}$ \\
\hline COD & $\mathrm{mg} / 1$ & $\begin{array}{l}\text { Phương pháp 8000, COD } \\
\text { dùng cho máy DR890, } \\
\text { dịch bởi Hach Việt Nam } \\
\text { hoặc TCVN 6491:1999 }\end{array}$ & 5 ngày /1 lần \\
\hline $\mathrm{NH}_{4}^{+}$ & $\mathrm{mg} / 1$ & $\begin{array}{l}\text { Theo chỉ dẫn của thiết bị } \\
\text { Method 10031 - Hach }\end{array}$ & $\begin{array}{c}5 \text { ngày } / 1 \\
\text { lần }\end{array}$ \\
\hline $\mathrm{pH}$ & - & $\begin{array}{l}\text { Đo bằng sensor, máy pH } \\
\text { cầm tay WTW 340i, Đức }\end{array}$ & $\begin{array}{c}\text { Đo hàng } \\
\text { ngày }\end{array}$ \\
\hline DO & $\mathrm{mg} / 1$ & $\begin{array}{l}\text { Đo bằng sensor, Máy đo } \\
\text { DO cầm tay, Oron, Mỹ }\end{array}$ & $\begin{array}{c}\text { Đo hàng } \\
\text { ngày }\end{array}$ \\
\hline Nhiệt độ & & Nhiệt kế thông thường & $\begin{array}{c}\text { Đo hàng } \\
\text { ngày }\end{array}$ \\
\hline
\end{tabular}

\section{Kết quả và thảo luận}

\subsection{Tải trọng hợp chất hữu cơ}

- Với nước thải tải trọng thấp OLR khoảng 1,0 - 1,2kgCOD/m³.ngày, kết quả thí nghiệm cho thấy hiệu quả XLNT rất tốt. Giai đoạn 1-5 ngày đầu tiên là giai đoạn khởi động của mô hình, bùn hạt hiếu khí cho vào chưa thích nghi hoàn toàn với môi trường trong bể nên hiệu suất xử lý chưa cao, với hiệu suất loại bỏ $57-60 \% \mathrm{COD}, 25-30 \% \mathrm{NH}^{+}{ }_{4}$-N. Trong các tuần tiếp theo do vi sinh vật trong bùn hạt đã dần thích nghi nên hiệu quả xử lý cũng tăng theo hiệu suất loại bỏ COD tăng từ $60 \%$ lên $90 \%, \mathrm{NH}^{+}{ }_{4}$-N tăng từ $45 \%$ lên $89 \%$ trong khoảng thời gian $10-25$ ngày. Đến giai đoạn tiếp theo, do bùn hạt đã thích nghi hoàn toàn với môi trường thí nghiệm nên hiệu quả xử lý cũng ổn định và luôn duy trì ở mức cao, với hiệu suất loại bỏ trên $92 \% \mathrm{COD}, 90 \% \mathrm{NH}^{+}{ }_{4}-\mathrm{N}$.
- Với nước thải tải trọng cao 2,7 - 3,0 kgCOD/m³.ngày, kết quả thí nghiệm cũng tương tự như đối với nước thải có tải trọng hữu cơ thấp. Hiệu quả loại bỏ bỏ trên $90 \% \mathrm{COD}, 89 \% \mathrm{NH}^{+}{ }_{4}{ }^{-} \mathrm{N}$.

Có thể thây, tải trọng hữu cơ ngoài việc cung cấp lượng cacbon cần thiết để phát triển sinh khối của vi sinh vật trong hệ phản ứng, còn kích thích hình thành bùn hạt, tạo điều kiện để phát triển hạt bùn có kích thước rõ ràng, cấu trúc đặc chắc, tăng khả năng XLNT của Bùn hạt hiếu khí. Kết quả nghiên cứu của các tác giả cũng phù hợp với kết quả nghiên cứu của Moy và cộng sự (2007) cho rằng sự ảnh hưởng của tải trọng hữu cơ lên hiệu quả XLNT của Bùn hạt hiếu khí là yếu tố quan trọng hàng đầu [2 - 4].

\subsection{Thời gian lắng}

Thời gian lắng có vai trò quan trọng đối với hiệu quả xử lý của trạm XLNT, nó ảnh hưởng trực tiếp đến thời gian của 1 chu kỳ xử lý trong hệ SBR. Khi thời gian lắng càng ngắn, những hạt bùn có khả năng lắng nhanh sẽ được lựa chọn, ngược lại những hạt bùn có khả năng lắng kém sẽ không lắng được và trôi theo dòng nước tại pha xả ra ngoài. Trong 55 ngày thực hiện thí nghiệm, nhóm nghiên cứu đã liên tục điều chỉnh giảm dần thời gian của pha lắng từ 30 phút xuống 20 phút. Kết quả cho thấy hiệu quả xử lý không giảm và đạt mức ổn định ở thời gian 20 phút. Điều này có thể lý giải như sau: Khi giảm thời gian lắng xuống, các bông bùn lơ lửng sẽ bị đào thải, đây là những bông bùn có khả năng xử lý nước thải kém. Những hạt bùn có khả năng lắng tốt hơn được giữ lại, đây là những hạt bùn có khả năng xử lý nước thải tốt hơn. Ngoài ra, trong giai đoạn này quá trình hình thành và phát triển của bùn hạt xảy ra mạnh mẽ hơn. Vì giai đoạn lắng và không cấp thêm nước thải vào gọi là "giai đoạn đói ăn của vi khuẩn". Giai đoạn này đóng một vai trò quan trọng đối với sự hình thành các hạt hiếu khí, đồng thời cũng là giai đoạn quan trọng đối với khả năng xử lý hiệu quả của bùn hạt hiếu khí. Sự hình thành Bùn hạt hiếu khí được bắt đầu bởi giai đoạn đói. Nó làm cho vi khuẩn ky nước hơn, thúc đẩy quá trình tạo hạt từ các bông bùn đây là cách thức tập hợp của các tế bào chống lại giai đoạn đói thức ăn. Khi bùn hạt tăng trưởng sinh khối thì khả năng loại bỏ các chất hữu cơ có trong nước thải cũng cao hơn. Tuy nhiên nếu thời gian lắng quá ngắn sẽ dẫn đến rửa trôi thêm nhiều hạt bùn, kéo theo hiệu suất làm việc chung của trạm XLNT giảm xuống, nên việc giảm thời gian lắng chỉ ở một mức độ nhất định. Đối với kết quả thí nghiệm của nhóm nghiên cứu thời gian lắng tối ưu là 20 phút. Kết quả nghiên cứu này cũng phù hợp với nhiều nghiên cứu trên thế giới đã nghiên cứu quá trình XLNT của bùn hạt hiếu khí trên công nghệ SBR với thời gian lắng 15 - 20 phút, kết quả loại bỏ các chất hữu cơ đạt hiệu quả cao, $\mathrm{COD}>90 \%[2-4]$.

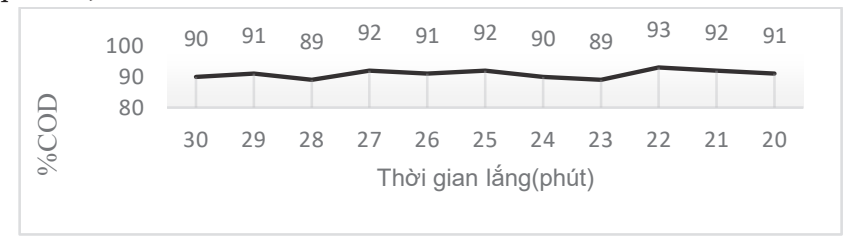

Hình 3. Mối liên hệ giữa thời gian lắng và hiệu quả xử lý của bùn hạt hiếu khí. 


\subsection{Lưu lượng sục khí}

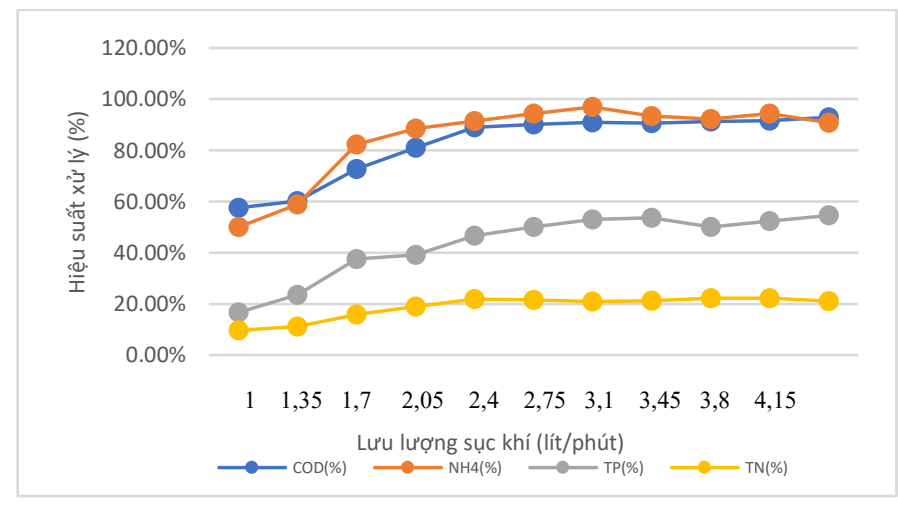

Hình 4. Mối liên hệ giữa lưu lượng sục khí và hiệu quả xử lý của bùn hạt hiếu khí.

Lưu lượng sục khí là một trong các yếu tố ảnh hưởng trực tiếp đến sự ổn định của bùn hạt hiếu khí. Giai đoạn $1-2$ tuần đầu làm thí nghiệm, nhóm nghiên cứu đã vận hành mô hình với lưu lượng sục khí là 1 - 1,5 (lít/phút). Tuy nhiên hiệu suất xử lý không cao COD $<60 \%, \mathrm{NH}^{+}{ }_{4}-\mathrm{N}<$ $58 \%$, T-N $<15 \%$, T-P $<20 \%$. Nhóm nghiên cứu đã điều chỉnh tăng dần lưu lượng sục khí về dần mức 1,5 - 4,5 (lít/phút), kết quả là hiệu suất xử lý tăng dần và đạt sự ổn định cao trong các tuần tiếp theo COD từ 60 - $92 \%, \mathrm{NH}_{4}{ }_{4}-\mathrm{N}$ từ $58-90 \%, \mathrm{~T}-\mathrm{N}$ từ $15-48 \%$, T-P từ $20-21 \%$. Tuy nhiên nếu tiếp tục tăng lưu lượng cấp khí vượt 5 (lít/phút) thì hiệu suất xử lý bắt đầu giảm dần. Hiện tượng này có thể giải thích như sau: Nếu lưu lượng sục khí quá lớn dẫn đến lực cắt tác động lên sự hình thành bùn hạt lớn, làm cho bùn hạt dễ vỡ, cấu trúc bùn hạt phát triển không ổn định. Vì vậy hiệu quả xử lý sẽ đạt hiệu quả không cao. Ngược lại nếu lưu lượng cấp khí quá nhỏ thì sẽ kích thích sự phát triển của các vi sinh vật ky khí, nên trong bể phản ứng các vi sinh vật hiếu khí không đủ sinh khối cần thiết để xử lý nước thải hiệu quả theo mong muốn. Từ kết quả thí nghiệm có thể thấy, hiệu suất xử lý đạt hiệu quả cao khi lưu lượng sục khí dao động $Q$ từ 1,5 - 4,5 (lít/phút). Kết quả này của nhóm nghiên cứu cũng tương đồng với nhiều kết quả nghiên cứu khác trên thế giới [3], [4], [6]. Việc tăng lưu lượng sục khí từ 2,5 (lít/phút) lên 3,5 (lít/phút) giúp tăng hiệu quả xử lý COD từ 80 \% lên trên 90 \% đối với nước thải đô thị tại Singapor. Mối liên hệ giữa lưu lượng sục khí và hiệu quả xử lý được thể hiện qua hình bên dưới.

\subsection{Nhiêt độ}

Trong thời gian 55 ngày làm thí nghiệm, điều kiện thí nghiệm là nhiệt độ phòng luôn biến đồi từ $25-35^{\circ} \mathrm{C}$. Qua các phân tích thí nghiệm, nhóm nghiên cứu thấy khi nhiệt độ dao động hiệu quả xử lý về cơ bản vẫn ổn định, nồng độ bùn và tốc độ lắng vẫn ổn định. Điều này chứng minh nhiệt độ môi trường ít ảnh hưởng đến hiệu quả làm việc của bùn hạt hiếu khí. Kết quả nghiên cứu cũng phù hợp với một số nghiên cứu trên thế giới như: nhóm nghiên cứu kết luận rằng nhiệt độ môi trường từ $25-35^{\circ} \mathrm{C}$ hầu như không ảnh hưởng đến hiệu quả xử lý của bùn hạt hiếu khí.

\section{5. Độ $p H$}

Thí nghiệm được thực hiện với nước thải đô thị có độ pH =6,1-
8,0, trong quá trình làm thí nghiệm nhóm tác giả nhận thấy rằng khi pH giảm, quá trình Nitrat và khử Nitơ diễn ra chậm hơn mặc dù các điều kiện thí nghiệm khác không thay đổi. Nguyên nhân do thiếu sự khử Nitơ trong bùn hạt, sự kết tủa hóa học của Phốt pho trong hạt có thể không xảy ra, do đó làm giảm mật độ hạt làm cho hạt lắng kém. Kết quả thí nghiệm của nhóm nghiên cứu cũng phù hợp với một số nghiên cứu trên thế giới [3], [4], [6]. Các đề tài này chứng minh khi pH càng thấp thì khả năng xử lý của bùn hạt càng kém và thiếu ổn định.

\section{Kết luận}

Tải trọng chất hữu cơ không ảnh hưởng nhiều đến hiệu quả XLNT của việc ứng dụng Bùn hạt hiếu khí trên mô hình công nghệ SBR. Hiệu suất loại bỏ trên $92 \% \mathrm{COD}, 90 \% \mathrm{NH}^{+}{ }_{4} \mathrm{~N}$. Kết quả này phù hợp với một số nghiên cứu cùng lĩnh vực trên thế giới.

Thời gian lắng có ảnh hưởng nhất định đến hiệu quả XLNT của việc ứng dụng Bùn hạt hiếu khí trên mô hình công nghệ SBR. Nếu thời gian lắng quá dài sẽ làm tăng thời gian của 1 chu kỳ hoạt động của bể, làm giảm công suất xử lý nước thải của trạm xử lý. Tuy nhiên nếu thời gian lắng quá ngắn sẽ dẫn đến rửa trôi thêm nhiều hạt bùn, kéo theo hiệu suất làm việc chung của trạm XLNT giảm xuống, nên việc giảm thời gian lắng chỉ ở một mức độ nhất định. Đối với kết quả thí nghiệm của nhóm nghiên cứu thời gian lắng tối ưu là 20 phút. Kết quả nghiên cứu này cũng phù hợp với nhiều nghiên cứu trên thế giới đã nghiên cứu quá trình XLNT của bùn hạt hiếu khí trên công nghệ SBR với thời gian lắng 15 - 20 phút, kết quả loại bỏ các chất hữu cơ đạt hiệu quả cao, COD > $90 \%$.

Lưu lượng sục khí có ảnh hưởng nhất định đến hiệu quả XLNT của việc ứng dụng Bùn hạt hiếu khí trên mô hình công nghệ SBR. Nếu lưu lượng sục khí lớn sẽ làm tăng chi phí trong vận hành, lưu lượng lớn sẽ làm vỡ cấu trúc của bùn hạt hiếu khí. Theo kết quả nghiên cứu của nhóm tác giả, lưu lượng sục khí tối ưu là 1,5 - 4,5(lít/phút).

Nhiệt độ môi trường từ $25-35^{\circ} \mathrm{C}$ hầu như không ảnh hưởng đến hiệu quả xử lý của bùn hạt hiếu khí. Kết quả này chứng minh bùn hạt hiếu khí phù hợp với điều kiện khí hậu Việt Nam.

Độ pH = 6,1 - 8,0 hầu như không ảnh hưởng đến hiệu quả xử lý của bùn hạt hiếu khí.

\section{Tài liệu tham khảo}

[1]. Liu Y, Yang SF, Tay JH. Elemental compositions and characteristics of aerobic granules cultivated at different substrate N/C ratios. Appl Microbiol Biotechnol, 61, 556.

[2]. Liu, Y.; Tay, JH. (2004) State of the art of biogranulation technology for wastewater treatment Biotechnology Advances, 22, 533

[3]. Liu, QS.; Liu, Y.; Tay, STL.; Show, KY.; Ivanov, V.; Moy, BYP. (2005) Startup of pilot-scale aerobic granular sludge reactor by stored granules. Environ Technol, 26, 1363.

[4]. 19. Boston: McGraw Hill. McSwain, BS.; Irvine, RL.; Wilderal, PA. (2003) The effect of intermittent feeding on aerobic granule structure. 5th International Conference on Biofilm Systems by International Water Association. South Africa: Cape Town.

[5]. Meyer, RL.; Saunders, AM.; Zeng, RJ.; Keller, J.; Blackall, LL. (2003) Microscale structure and function of anaerobic-aerobic granules containing

[6]. Adav SS, Lee DJ, Show KY, Tay JH. Aerobic granular sludge: recent advances. Biotechnol Adv 2008;26:411-23. 